\title{
$t(14 ; 18)$-negative follicular lymphomas are associated with a high frequency of BCL6 rearrangement at the alternative breakpoint region
}

Keni Gu${ }^{1}$, Kai Fu ${ }^{1}$, Smrati Jain ${ }^{2}$, Zhongfen $\mathrm{Liu}^{1}$, Javeed Iqbal ${ }^{1}$, Min $\mathrm{Li}^{1}$, Warren G Sanger ${ }^{2}$, Dennis D Weisenburger ${ }^{1}$, Timothy C Greiner ${ }^{1}$, Patricia Aoun ${ }^{1}$, Bhavana J Dave ${ }^{2}$ and Wing C Chan ${ }^{1}$

${ }^{1}$ Department of Pathology and Microbiology, University of Nebraska Medical Center, Omaha, NE, USA and ${ }^{2}$ Center for Human Genetics, Department of Pediatrics, University of Nebraska Medical Center, Omaha, NE, USA

\begin{abstract}
A frequent chromosomal translocation in mature B-cell non-Hodgkin lymphoma affects band 3q27 and results in the deregulation of the B-cell lymphoma $6(B C L 6)$ gene. Two breakpoint clusters have been described thus far, the major breakpoint region (MBR) and an alternative breakpoint region (ABR) that is located 245-285 kb $5^{\prime}$ to $B C L 6$. Translocation at the MBR predominates in diffuse large B-cell lymphoma, whereas translocation at the $A B R$ is reported to be frequently associated with grade $3 B$ follicular lymphoma. However, translocation at the $A B R$ has not been studied in a large series of follicular lymphomas, particularly $t(14 ; 18)$-negative follicular lymphomas. Therefore, we studied BLC6 rearrangements at the MBR and ABR by using breakapart fluorescence in situ hybridization (FISH) probes in 142 cases of follicular lymphomas, including 63 $t(14 ; 18)$-negative and $79 t(14 ; 18)$-positive cases. Conventional cytogenetic (karyotype) analysis was also performed in 58 of the $63 \mathrm{t}(14 ; 18)$-negative cases. BCL6 rearrangement was found in $26 \%$ of $t(14 ; 18)$-negative and $19 \%$ of $t(14 ; 18)$-positive follicular lymphoma. $t(14 ; 18)$-negative cases showed a high frequency of rearrangement at the $A B R(12 \%)$ with an $A B R / M B R$ ratio of 0.86 , compared with only $5 \%$ with an ABR/MBR ratio of 0.36 in the $t(14 ; 18)$-positive cases. BCL6 rearrangements were found in all grades of follicular lymphoma but were most frequent in grade $3 \mathrm{t}(14 ; 18)$-negative follicular lymphoma $(60 \%)$. FISH analysis had a higher sensitivity for detecting BCL6 rearrangements than conventional cytogenetics. In conclusion, BCL6 rearrangements occur at a similar frequency in $t(14 ; 18)$-negative follicular lymphoma and diffuse large $B$-cell lymphoma. However, $t(14 ; 18)$-negative follicular lymphoma appears to have a higher frequency of rearrangement at the ABR compared with $t(14 ; 18)$-positive follicular lymphoma and diffuse large B-cell lymphoma. Therefore, it is important to perform FISH analysis with ABR to determine possible involvement of BCL6 rearrangement in follicular lymphoma, especially in $t(14 ; 18)$-negative cases.
\end{abstract}

Modern Pathology (2009) 22, 1251-1257; doi:10.1038/modpathol.2009.81; published online 22 May 2009

Keywords: $\mathrm{t}(14 ; 18)$; follicular lymphoma; fluorescence in situ hybridization; BCL6 rearrangement; major breakpoint region; alternative breakpoint region

Follicular lymphoma is a neoplasm of germinal center B cells and comprises about $20 \%$ of all

Correspondence: Professor WC Chan, MD, Department of Pathology and Microbiology, University of Nebraska, 983135 Nebraska Medical Center, Omaha, NE 68198-3135, USA.

E-mail: jchan@unmc.edu

or Dr BJ Dave, PhD, FACMG, Human Genetics Laboratory, Department of Pediatrics and Pathology, Munroe Meyer Institute, University of Nebraska Medical Center, Omaha, NE 68198-5440, USA.

E-mail: bdave@unmc.edu

Received 7 January 2009; revised 17 April 2009; accepted 18 April 2009; published online 22 May 2009 lymphomas with the highest incidence in the United States and Western Europe. It affects primarily adults, with a median age in the sixth decade and a male/female ratio of $1: 1.7 .^{1}$ Follicular lymphoma is generally considered to be an indolent, but incurable disease, with a median overall survival of 7-10 years. Transformation to an aggressive B-cell lymphoma occurs in about $25-35 \%$ of cases and is associated with a poor outcome. ${ }^{1}$ A chromosomal translocation, $\mathrm{t}(14 ; 18)(\mathrm{q} 32 ; \mathrm{q} 21)$, is the genetic hallmark of follicular lymphoma. This translocation can be identified in $85-90 \%$ of nodal follicular lymphoma cases. $^{2}$ Juxtaposition of the B-cell 
leukemia/lymphoma 2 gene (BCL2) at chromosome $18 q 21$ and the immunoglobulin heavy chain gene $(\mathrm{IgH})$ at $14 \mathrm{q} 32$ results in the deregulation of $B C L 2$, an antiapoptotic protein. Additional genetic alterations result in progression to follicular lymphoma. ${ }^{3,4}$ However, $10-15 \%$ of cases do not harbor the $\mathrm{t}(14 ; 18)(\mathrm{q} 32 ; \mathrm{q} 21)$ and in these $\mathrm{t}(14 ; 18)$-negative cases, other mechanisms are thought to be involved in the pathogenesis.

A frequent chromosomal translocation in mature B-cell lymphoma is a rearrangement affecting chromosomal band $3 \mathrm{q} 27$, which results in the deregulation of expression of $B C L 6$, a human proto-oncogene. ${ }^{5,6} B C L 6$ encodes a $95 \mathrm{kd}$ nuclear zinc-finger phosphoprotein, which functions as a sequence-specific transcriptional repressor. ${ }^{7}$ Chromosome 3q27 rearrangement/BCL6 translocation is frequently found in diffuse large B-cell lymphoma, at a frequency of $25-37 \%$, depending on the detection methods used and patient population studied. ${ }^{8-10}$ BCL6 translocations have also been reported at a lower frequency in follicular lymphoma (13 and $14.3 \%)^{8,10}$ The highest frequency of $B C L 6$ translocation has been reported in grade 3B follicular lymphoma (44\%). ${ }^{11}$ Interestingly, a higher frequency of 3q27 abnormalities $(22 \%)$ was also found in $\mathrm{t}(14 ; 18)$-negative follicular lymphoma, ${ }^{12,13}$ including the $\mathrm{t}(3 ; 14)(\mathrm{q} 27 ; \mathrm{q} 32)$, suggesting an important role for $B C L 6$ in $\mathrm{t}(14 ; 18)$-negative follicular lymphoma. ${ }^{12,13}$

In addition to translocation at the major breakpoint region (MBR) that encompasses the noncoding first exon and part of the first intron of BCL6, an alternative breakpoint region (ABR) located 245$285 \mathrm{~kb} 5^{\prime}$ to $B C L 6$ has been described. ${ }^{14,15}$ Translocations of $B C L 6$ involving the ABR were reported to be associated with grade $3 \mathrm{~B}$ follicular lymphoma. ${ }^{16}$ However, translocation at the ABR has not been examined in a large series of follicular lymphoma, particularly in $t(14 ; 18)$-negative cases. The aim of this study was to determine the frequency of $B C L 6$ rearrangements at the MBR and ABR in a series of well-defined $t(14 ; 18)$-negative and $t(14 ; 18)$-positive follicular lymphoma cases. We have used breakapart fluorescence in situ hybridization (FISH) probes for the MBR and ABR of BCL6. The splitting of the FISH signals could be caused by many different cytogenetic rearrangements occurring in that region, including translocations, inversions and insertions; we will therefore use the term 'rearrangement' for all subsequent discussions. We also compared these results with our previously published study of diffuse large B-cell lymphoma. ${ }^{17}$

\section{Materials and methods}

\section{Patient Population}

We selected 142 cases of follicular lymphoma (from the year 1982 to 2005), including $63 \mathrm{t}(14 ; 18)$ negative and $79 \mathrm{t}(14 ; 18)$-positive cases. Briefly, we retrieved all $\mathrm{t}(14 ; 18)$-negative follicular lymphoma cases from our cytogenetic database and the selected cases were further verified by FISH analysis to confirm the $t(14 ; 18)$ status. For $t(14 ; 18)$-positive follicular lymphoma cases, the selection criteria were based on either conventional karyotype analysis or FISH analysis. The diagnosis of follicular lymphoma was confirmed by at least two hematopathologists in all cases. The Institutional Review Board of the University of Nebraska Medical Center approved this study.

\section{FISH Analysis}

Interphase FISH analysis for BCL6 rearrangements was performed on the 142 cases using tissue microarrays made from formalin-fixed, paraffinembedded tissue blocks, as described earlier. ${ }^{17}$ Briefly, hematoxylin and eosin-stained sections from each tissue block were used to define diagnostic areas, and three representative $0.6-\mathrm{mm}$ cores were obtained from each case. Only follicular lymphoma components were selected for FISH studies in the composite lymphomas cases. A BCL6 break-apart probe (Abbott-Vysis, Downers Grove, IL, USA) was used to detect BCL6 rearrangement at the MBR, and a home-brew break-apart probe (Clones RP11-1144D2 and RP11-76L15, kindly provided by WL Lam and RJ deLeeuw) was used for rearrangement at the ABR (Figure 1). Nuclei were counterstained with 4,6-diamidino-2-phenylindole (DAPI) in Antifade solution and the slides were visualized using an Olympus BX51 fluorescence microscope. Images were captured and archived using CytoVision software (Applied Imaging, Santa Clara, CA, USA). To analyze the hybridization, a total of 50-100 nuclei per case were scored for the presence of the BCL6 rearrangement. A cutoff for positive FISH assays for both the MBR and ABR was established to be more than $20 \%$. Interphase FISH analysis for BCL2 rearrangement was also performed using a BCL2 break-apart probe (Abbott-Vysis, Downers Grove, IL, USA) with a positive cutoff of $20 \%$. Any ambiguous FISH results

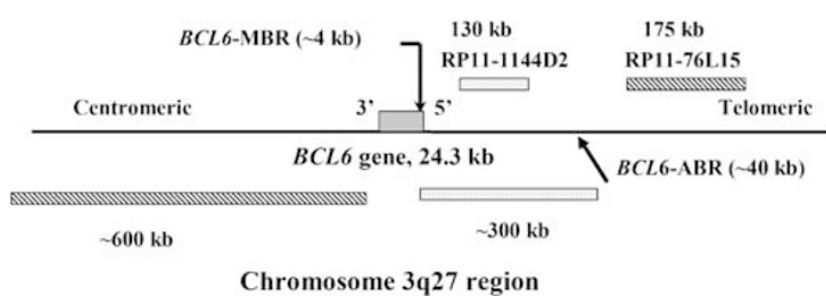

$\square$ BCL6gene $\quad \square$ बimm FISH break-apart probes

Figure 1 Diagram of positions of FISH probes for BCL6 rearrangements at the MBR and ABR of chromosome 3q27. FISH: fluorescence in situ hybridization, MBR: major breakpoint region, ABR: alternative breakpoint region. 
from the tissue microarrays were repeated using unstained whole tissue sections.

\section{Conventional Cytogenetic Analysis}

Karyotypes were available in 58 of the $63 \mathrm{t}(14 ; 18)$ negative follicular lymphoma cases. Cytogenetic analysis was performed according to a previously described protocol. ${ }^{18}$ When available, at least 20 metaphases were analyzed. Karyotypes of Giemsabanded chromosomes were described according to the International System for Human Cytogenetic Nomenclature (ISCN 2005).

\section{Statistical Analysis}

Fisher's exact test was used to calculate $P$-value in the statistical analysis.

\section{Results}

Sixty-three $\mathrm{t}(14 ; 18)$-negative cases of follicular lymphoma had a median age of 62 years (range, 24-86 years; $59 \%$ female and $41 \%$ male). BCL2 rearrangement status was verified by BCL2 FISH analysis in all $\mathrm{t}(14 ; 18)$-negative follicular lymphoma cases. A total of 112 FISH assays for the $B C L 6$ rearrangements yielded interpretable results, including $63 \mathrm{MBR}$ and 49 ABR studies. There were a total of $79 \mathrm{t}(14 ; 18)-$ positive cases of follicular lymphoma with a median age 55 years (range, 34-89 years; $48 \%$ female and $52 \%$ male). In these $t(14 ; 18)$-positive cases, a total of 117 FISH assays for the BCL6 rearrangements yielded interpretable results, including 79 MBR and $38 \mathrm{ABR}$ studies. A higher technical failure rate was noted in BCL6 ABR FISH studies.

The frequency of the BCL6 rearrangement was $26 \%$ in $\mathrm{t}(14 ; 18)$-negative follicular lymphoma (BCL6-MBR: $14 \%, B C L 6-A B R: 12 \%$ ) and $19 \%$ in $\mathrm{t}(14 ; 18)$-positive follicular lymphoma (BCL6-MBR: 14\%, BCL6-ABR: 5\%) (Table 1). We found that $\mathrm{t}(14 ; 18)$-negative follicular lymphoma appeared to have a higher frequency of rearrangement at the ABR with an ABR/MBR ratio of 0.86 , compared with $\mathrm{t}(14 ; 18)$-positive follicular lymphoma (ABR/MBR ratio of 0.36 ) and diffuse large B-cell lymphoma (ABR/MBR ratio of 0.32 ). ${ }^{17}$ There was no statistically significant difference detected in the distribution of $B C L 6$-ABR rearrangement positive cases between the two groups $(\mathrm{t}(14 ; 18)$-negative and $\mathrm{t}(14 ; 18)$ positive cases) $(P=0.46)$.

A comparison of clinical features, histological grade and the rearrangement status of BCL6 in the $\mathrm{t}(14 ; 18)$-negative and $\mathrm{t}(14 ; 18)$-positive follicular lymphoma is listed in Table 2 . The $\mathrm{t}(14 ; 18)$-negative follicular lymphoma group contains a higher frequency of grade 3 cases than $\mathrm{t}(14 ; 18)$-positive follicular lymphoma group (57 vs $37 \%, P=0.02$ ). $B C L 6$ rearrangements were found in all grades of follicular lymphoma, but were the highest in grade 3 $\mathrm{t}(14 ; 18)$-negative follicular lymphoma cases $(60 \%)$ (Table 2).

The distribution of BCL6 rearrangement was analyzed in grade 3 follicular lymphoma cases, particularly in grade 3 cases with a diffuse large Bcell lymphoma component. Owing to higher technical failure rate in the BCL6 ABR FISH analysis, only $49 \mathrm{t}(14 ; 18)$-negative follicular lymphoma cases had interpretable FISH assays for the BCL6-MBR and BCL6-ABR rearrangements, and only two cases were grade $3 \mathrm{~B}$, both of which also contained a diffuse large B-cell component. One (case no. 15, Table 3) had a BCL6-MBR rearrangement. Twentyeight of the 49 cases were grade $3 \mathrm{~A}$ and half of the 28 cases had a diffuse large B-cell component. Among these 14 cases, one had BCL6-ABR rearrangement and four had BCL6-MBR rearrangement (Table 3).

Similarly, in the $38 \mathrm{t}(14 ; 18)$-positive follicular lymphoma cases with interpretable FISH assays for both the BCL6-MBR and BCL6-ABR rearrangements, only two cases were grade $3 \mathrm{~B}$, both of which also contained a diffuse large B-cell lymphoma component, and one of these two cases had a BCL6-MBR rearrangement. Twelve of the 38 cases were grade $3 \mathrm{~A}$ and 3 of the 12 cases had a diffuse large B-cell lymphoma component, and one of these three cases had a BCL6-ABR rearrangement. Thus, none of the follicular lymphoma 3B cases studied had BCL6-ABR rearrangement. The numbers of positive cases in each group are too small for statistical analysis.

Table 1 FISH analysis for BCL6 rearrangements at the MBR and ABR among t(14;18)-positive FL, t(14;18)-negative FL and DLBCL cases

\begin{tabular}{|c|c|c|c|c|c|c|}
\hline \multirow[b]{2}{*}{ FISH results } & \multicolumn{2}{|c|}{$t(14 ; 18)-p o s . F L$} & \multicolumn{2}{|c|}{ t(14;18)-neg. FL } & \multicolumn{2}{|c|}{$D L B C L^{\mathrm{a}}$} \\
\hline & BCL6 MBR & BCL6 ABR & BCL6 MBR & $B C L 6$ ABR & BCL6 MBR & $B C L 6 A B R$ \\
\hline Positive cases & 11 & 2 & 9 & 6 & 25 & 5 \\
\hline Negative cases & 68 & 36 & 54 & 43 & 108 & 73 \\
\hline Total cases & 79 & 38 & 63 & 49 & 133 & 78 \\
\hline Positive cases (\%) & 14 & 5 & 14 & 12 & 19 & 6 \\
\hline
\end{tabular}

${ }^{\mathrm{a}}$ From our previously published data. ${ }^{17}$

FL: follicular lymphoma, DLBCL: diffuse large B-cell lymphoma, pos.: positive, neg.: negative, MBR: major breakpoint region, ABR: alternative breakpoint region. 
Table 2 Comparison of age, gender, sites of involvement, histological grade and BCL6 rearrangement status in $\mathrm{t}(14 ; 18)$-positive and $\mathrm{t}(14 ; 18)$-negative FL

\begin{tabular}{|c|c|c|c|c|c|c|c|c|}
\hline & \multicolumn{4}{|c|}{$t(14 ; 18)-p o s . F L$} & \multicolumn{4}{|c|}{ t(14;18)-neg. FL } \\
\hline & $\begin{array}{l}\text { Total } \\
\text { cases }\end{array}$ & $B C L 6 R$ & $\begin{array}{l}\text { BCL6 R } \\
\text { at } M B R\end{array}$ & $\begin{array}{l}B C L 6 R \\
\text { at } A B R\end{array}$ & Total cases & $B C L 6 R$ & $\begin{array}{l}\text { BCL6 R } \\
\text { at } M B R\end{array}$ & $\begin{array}{l}B C L 6 R \\
\text { at } A B R\end{array}$ \\
\hline $\begin{array}{l}\text { Age range } \\
\text { (median) }\end{array}$ & $\begin{array}{c}34-89 \\
(55)\end{array}$ & $\begin{array}{c}38-80 \\
(56)\end{array}$ & $\begin{array}{c}44-80 \\
(56)\end{array}$ & $\begin{array}{c}38-79 \\
(59)\end{array}$ & $\begin{array}{c}24-86 \\
(62)\end{array}$ & $\begin{array}{c}29-83 \\
(63)\end{array}$ & $\begin{array}{c}29-83 \\
(58)\end{array}$ & $\begin{array}{c}41-73 \\
(68)\end{array}$ \\
\hline Female & $48 \%$ & $31 \%$ & $36 \%$ & $0 \%$ & $59 \%$ & $87 \%$ & $100 \%$ & $67 \%$ \\
\hline Nodal & $87 \%$ & $85 \%$ & $82 \%$ & $100 \%$ & $78 \%$ & $87 \%$ & $78 \%$ & $100 \%$ \\
\hline Grade 3 & $37 \%$ & $46 \%$ & $45 \%$ & $50 \%$ & $57 \%$ & $60 \%$ & $56 \%$ & $67 \%$ \\
\hline Grade 1-2 & $63 \%$ & $54 \%$ & $55 \%$ & $50 \%$ & $43 \%$ & $40 \%$ & $44 \%$ & $33 \%$ \\
\hline Total cases & 79 & 13 & 11 & 2 & 63 & 15 & 9 & 6 \\
\hline
\end{tabular}

FL: follicular lymphoma, pos.: positive, neg.: negative, R: rearrangement, MBR: major breakpoint region, ABR: alternative breakpoint region.

Table 3 Comparison of conventional cytogenetics and FISH analysis for BCL6 rearrangement in t(14;18)-negative FL cases

\begin{tabular}{llllll}
\hline Case & Age & Gender & Diagnosis & $\begin{array}{l}\text { Cytogenetic abnormality } \\
\text { involving chromosome } 3\end{array}$ & $\begin{array}{l}\text { FISH- } \\
\text { BCL6-MBR }\end{array}$ \\
\hline 1 & & & FISH- \\
BCL6-ABR
\end{tabular}

FL: follicular lymphoma, DLBCL: diffuse large B-cell lymphoma, pos.: positive, neg.: negative, MBR: major breakpoint region, ABR: alternative breakpoint region, NR: no results.

*One BCL6 signal is deleted.

Conventional cytogenetic (karyotype) results were available in 58 of the $63 \mathrm{t}(14 ; 18)$-negative follicular lymphoma cases. Eleven of these 58 cases showed either trisomy 3 or a chromosomal translocation involving band 3q27. Table 3 displays 21 cases that had either BCL6 rearrangements detected by FISH (15 cases) or cytogenetic abnormalities by karyotype analysis. Three of these 15 cases also had a chromosomal translocation involving 3q27 identified by karyotype analysis, with two cases having $t(3 ; 22)(q 27 ; q 11.2)$ and one $t(3 ; 14)(q 27 ; q 32)$. Of the remaining 12 cases, one contained a chromosomal translocation involving 3q29 and three had trisomy 3. Karyotype analysis results were not available in the $t(14 ; 18)$-positive follicular lymphoma cases; therefore, comparison between karyotype analysis and FISH studies was not performed.

\section{Discussion}

Chromosomal translocation involving band 3q27 $(B C L 6)$ is common in diffuse large B-cell lymphoma and is recognized to be pathogenetically significant. ${ }^{19}$ This translocation is also seen in other B-cell non-Hodgkin lymphoma, mainly in follicular lymphoma, but also in marginal zone lymphoma. ${ }^{20}$ However, most studies of BCL6 translocation by FISH or Southern blot analysis in follicular lymphoma did not include probe(s) for the BCL6-ABR rearrangement. ${ }^{8-10,13}$ Translocation at the ABR has been reported to occur more frequently in follicular lymphoma $(2 / 20,10 \%)$ than in diffuse large B-cell lymphoma $(2 / 84,2.4 \%){ }^{15}$ This finding questions the reported incidence of $B C L 6$ translocation, especially in follicular lymphoma when the ABR was not 
examined. Therefore, we examined a large series of well-defined $\mathrm{t}(14 ; 18)$-negative and $\mathrm{t}(14 ; 18)$-positive follicular lymphoma for BCL6 rearrangement at the MBR and ABR by FISH analysis. Our study shows an overall frequency of BCL6 rearrangement of $26 \%$ in $\mathrm{t}(14 ; 18)$-negative and $19 \%$ in $\mathrm{t}(14 ; 18)$-positive follicular lymphoma. For the MBR alone, the frequency of BCL6 rearrangement is very similar between $\mathrm{t}(14 ; 18)$-negative and $\mathrm{t}(14 ; 18)$-positive follicular lymphoma (Table 1). Using FISH analysis, Diaz-Alderete et $a l^{21}$ also reported similar frequencies of $B C L 6$ rearrangement at the MBR in $t(14 ; 18)$-negative $(14.6 \%)$ and $t(14 ; 18)$-positive follicular lymphoma $(13.1 \%)$. In addition, we found that the frequency of BCL6 rearrangement at the ABR appeared to be higher in $\mathrm{t}(14 ; 18)$-negative $(12 \%)$ than in $\mathrm{t}(14 ; 18)$ positive follicular lymphoma (5\%) (Table 1). There is only a trend that $\mathrm{t}(14 ; 18)$-negative follicular lymphomas are associated with a higher frequency of BCL6ABR rearrangement, although there was no statistically significant difference for this rearrangement between $t(14 ; 18)$-negative cases and $t(14 ; 18)$-positive cases due to the overall low incidence of BCL6 rearrangements at the $\mathrm{MBR}$ and $\mathrm{ABR}$.

The BCL6-ABR rearrangement occurred in all grades of follicular lymphoma but was most frequent in grade $3 \mathrm{t}(14 ; 18)$-negative follicular lymphoma cases (67\%) (Table 2). In a smaller series, Bosga-Bouwer et al $^{16}$ selected eight cases of grade 3B follicular lymphoma with cytogenetic abnormalities at the 3q27 and reported that the ABR translocation was found in six of these cases. However, in our series of 87 follicular lymphoma cases with interpretable FISH assays for both the BCL6-MBR and $B C L 6$-ABR rearrangements, none of the four cases of grade 3B follicular lymphoma (2 $t(14 ; 18)$-negative and two t(14;18)-positive) had a BCL6-ABR rearrangement. Although BCL6 rearrangement was common in grade 3 follicular lymphoma, especially in $\mathrm{t}(14 ; 18)$-negative cases, we did not observe a high frequency in grade $3 \mathrm{~B}$ cases. However, the number of $3 \mathrm{~B}$ follicular lymphoma is small and this issue needs further investigation.

We also found the overall frequency of BCL6 rearrangement in $\mathrm{t}(14 ; 18)$-negative follicular lymphoma (26\%) to be similar to that of our previously published study for diffuse large B-cell lymphoma cases $(25 \%),{ }^{17}$ suggesting that BCL6 may also be pathogenetically significant in $\mathrm{t}(14 ; 18)$-negative follicular lymphoma. However, $\mathrm{t}(14 ; 18)$-negative follicular lymphoma had a higher frequency of BCL6 rearrangement at the ABR, whereas diffuse large $\mathrm{B}$ cell lymphoma more frequently used the MBR. We found that the intergenic region around the ABR is actively transcribed, with transcripts found in germinal center B-cell lines but not in cell lines at other stages of B-cell differentiation (data not shown). The chromatin structure in germinal center B cells may, therefore, permit rearrangements to occur at this location. However, why this region is preferentially used in $t(14 ; 18)$-negative follicular lymphoma and the mechanism of rearrangement is not currently understood.

The mechanism of dysregulation of BCL6 expression due to $B C L 6$ rearrangement at the MBR has been extensively investigated. Chromosomal translocations at the MBR place the intact coding region of BCL6 under the control of heterologous promoters derived from partner chromosomes, resulting in deregulated expression of $B C L 6 .{ }^{22-24}$ Moreover, most rearrangements at the MBR remove the first noncoding exon of the BCL6 gene that contains two BCL6-binding sites, and thus disrupt a negative autoregulatory circuit. ${ }^{25,26}$ Some of the rearrangements may also disrupt an interferon regulatory factor 4 (IRF4) responsive region in the first intron of BCL6 and block its downregulation by CD40 signaling. ${ }^{27}$ In contrast, chromosomal rearrangements at the ABR leave the regulatory regions intact in the first exon and first intron of BCL6. Thus, rearrangement at the ABR must introduce a strong enhancer signal to dysregulate BCL6 expression. It has been reported that diffuse large B-cell lymphoma and follicular lymphoma cases with ABR rearrangement expressed BCL6 at levels comparable with phenotypically similar cases with MBR rearrangement or with no 3q27 abnormality. ${ }^{15}$

It should be noted that the dysregulation of BCL6 expression may also result from mutations introduced by the somatic hypermutation mechanism affecting the $5^{\prime}$ regulatory region of $B C L 6$, as noted above. ${ }^{25}$ Thus, the frequency of cases with dysregulated $B C L 6$ expression may be significantly higher than the frequency of cases with BCL6 rearrangement. Also, rearranged cases with a preserved $5^{\prime}$ regulatory region may be further affected by these mutations.

Discrepancies between FISH analysis and conventional cytogenetics (karyotype study) were not infrequent in our study. The possible explanations include: (1) 3q27 rearrangements not involving the MBR and ABR regions, (2) compromised morphology of tumor chromosomes making it difficult to recognize rearrangements near the telomeric end of $3 q$, (3) the rearrangement involving 3q27 are hidden in partially characterized karyotypes containing 'add' (additional uncharacterized chromosomal material) or 'marker' chromosomes. ${ }^{28}$

In summary, our study shows that the frequency of the BCL6 rearrangement is similar in $\mathrm{t}(14 ; 18)$ negative follicular lymphoma and diffuse large B-cell lymphoma. However, t(14;18)-negative follicular lymphoma has a higher frequency of BCL6 rearrangement at the $\mathrm{ABR}$, whereas $\mathrm{t}(14 ; 18)$-positive follicular lymphoma and diffuse large B-cell lymphoma more frequently use the MBR than the ABR. Therefore, it is important to include the ABR for FISH analysis of BCL6 rearrangements in follicular lymphoma, especially in $\mathrm{t}(14 ; 18)$-negative cases.

The high frequency of $B C L 6$ rearrangement in $\mathrm{t}(14 ; 18)$-negative follicular lymphoma suggests that BCL6 could play an important role in the 
lymphomagenesis. The mechanism of BCL6 rearrangement at the ABR is currently under investigation and may explain the differential usage of this breakpoint in the different lymphomas. How rearrangements at the far 5'ABR affect BCL6 expression is intriguing and requires further study.

\section{Acknowledgements}

Statistical analysis was performed by Lynette Smith, MS, statistical coordinator, Department of Biostatistics, SLC 3040, 983135 Nebraska Medical Center, Omaha, NE 68198-4375, and Lixin Zhang, PhD, Department of Epidemiology and Center for Molecular and Clinical Epidemiology of Infectious Diseases, University of Michigan, 109 Observatory Street, Ann Arbor, MI 48109-2029. This study was supported in part by an NCI grant (5U01/CA 114778).

\section{Conflict of interest}

All authors have no significant financial or other relationship (which may be perceived as influencing the content, or conclusions reached) with the commercial enterprise whose products and/or services are discussed in this paper.

\section{References}

1 Nathwani BN, Harris NL, Weisenburger DD, et al. Follicular lymphoma. In: Jaffe ES, Harris NL, Stein H, Vardiman JW (eds). World Health Organization Classification of Tumors. Pathology and Genetics of Tumors of Haematopoietic and Lymphoid Tissues. IARC Press: Lyon, 2001;162-167.

2 Aster JC, Longtine JA. Detection of BCL2 rearrangements in follicular lymphoma. Am J Pathol 2002;160:759-763.

3 Winter JN, Gascoyne RD, Van Besien K. Low-grade lymphoma. Hematology Am Soc Hematol Educ Program 2004;203-220.

4 d'Amore F, Chan E, Iqbal J, et al. Clonal evolution in $\mathrm{t}(14 ; 18)$-positive follicular lymphoma, evidence for multiple common pathways, and frequent parallel clonal evolution. Clin Cancer Res 2008;14:7180-7187.

5 Baron BW, Nucifora G, McCabe N, et al. Identification of the gene associated with the recurring chromosomal translocations $\mathrm{t}(3 ; 14)(\mathrm{q} 27 ; \mathrm{q} 32)$ and $\mathrm{t}(3 ; 22)(\mathrm{q} 27 ; \mathrm{q} 11)$ in B-cell lymphomas. Proc Natl Acad Sci USA 1993;90:5262-5266.

6 Ye BH, Lista F, Lo Coco F, et al. Alterations of a zinc finger-encoding gene, BCL-6, in diffuse large-cell lymphoma. Science 1993;262:747-750.

7 Chang CC, Ye BH, Chaganti RS, et al. BCL-6, a POZ/ zinc-finger protein, is a sequence-specific transcriptional repressor. Proc Natl Acad Sci USA 1996;93:6947-6952.

8 Bastard C, Deweindt C, Kerckaert JP, et al. LAZ3 rearrangements in non-Hodgkin's lymphoma: correlation with histology, immunophenotype, karyotype, and clinical outcome in 217 patients. Blood 1994;83:2423-2427.

9 Katzenberger $\mathrm{T}$, Ott $\mathrm{G}$, Klein $\mathrm{T}$, et al. Cytogenetic alterations affecting BCL6 are predominantly found in follicular lymphomas grade $3 \mathrm{~B}$ with a diffuse large B-cell component. Am J Pathol 2004;165: $481-490$.

10 Otsuki T, Yano T, Clark HM, et al. Analysis of LAZ3 (BCL-6) status in B-cell non-Hodgkin's lymphomas: results of rearrangement and gene expression studies and a mutational analysis of coding region sequences. Blood 1995;85:2877-2884.

11 Ott G, Katzenberger T, Lohr A, et al. Cytomorphologic, immunohistochemical, and cytogenetic profiles of follicular lymphoma: 2 types of follicular lymphoma grade 3. Blood 2002;99:3806-3812.

12 Horsman DE, Okamoto I, Ludkovski O, et al. Follicular lymphoma lacking the $\mathrm{t}(14 ; 18)(\mathrm{q} 32 ; \mathrm{q} 21)$ : identification of two disease subtypes. Br J Haematol 2003;120: 424-433.

13 Jardin F, Gaulard P, Buchonnet G, et al. Follicular lymphoma without $\mathrm{t}(14 ; 18)$ and with BCL-6 rearrangement: a lymphoma subtype with distinct pathological, molecular and clinical characteristics. Leukemia 2002;16:2309-2317.

14 Chen W, Butler M, Rao PH, et al. The t(2;3)(q21;q27) translocation in non-Hodgkin's lymphoma displays BCL6 mutations in the $5^{\prime}$ regulatory region and chromosomal breakpoints distant from the gene. Oncogene 1998;17:1717-1722.

15 Butler MP, Iida S, Capello D, et al. Alternative translocation breakpoint cluster region $5^{\prime}$ to BCL-6 in B-cell non-Hodgkin's lymphoma. Cancer Res 2002;62:4089-4094.

16 Bosga-Bouwer AG, Haralambieva E, Booman M, et al. BCL6 alternative translocation breakpoint cluster region associated with follicular lymphoma grade 3B. Genes Chromosomes Cancer 2005;44:301-304.

17 Iqbal J, Greiner TC, Patel K, et al. Distinctive patterns of BCL6 molecular alterations and their functional consequences in different subgroups of diffuse large B-cell lymphoma. Leukemia 2007;21:2332-2343.

18 Dave BJ, Hess MM, Pickering DL, et al. Rearrangements of chromosome band 1p36 in non-Hodgkin's lymphoma. Clin Cancer Res 1999;5:1401-1409.

19 Cattoretti G, Pasqualucci L, Ballon G, et al. Deregulated BCL6 expression recapitulates the pathogenesis of human diffuse large B cell lymphomas in mice. Cancer Cell 2005;7:445-455.

20 Ye H, Remstein ED, Bacon CM, et al. Chromosomal translocations involving BCL6 in MALT lymphoma. Haematologica 2008;93:145-146.

21 Diaz-Alderete A, Doval A, Camacho F, et al. Frequency of BCL2 and BCL6 translocations in follicular lymphoma: relation with histological and clinical features. Leuk Lymphoma 2008;49:95-101.

22 Chen W, Iida S, Louie DC, et al. Heterologous promoters fused to BCL6 by chromosomal translocations affecting band 3q27 cause its deregulated expression during B-cell differentiation. Blood 1998;91:603-607.

23 Ohno H. Pathogenetic and clinical implications of non-immunoglobulin; BCL6 translocations in B-cell non-Hodgkin's lymphoma. J Clin Exp Hematop 2006; 46:43-53.

24 Ye BH, Chaganti S, Chang CC, et al. Chromosomal translocations cause deregulated BCL6 expression by 
promoter substitution in B cell lymphoma. EMBO J 1995;14:6209-6217.

25 Pasqualucci L, Migliazza A, Basso K, et al. Mutations of the BCL6 proto-oncogene disrupt its negative autoregulation in diffuse large B-cell lymphoma. Blood 2003;101:2914-2923.

26 Wang X, Li Z, Naganuma A, et al. Negative autoregulation of BCL-6 is bypassed by genetic alterations in diffuse large B cell lymphomas. Proc Natl Acad Sci USA 2002;99:15018-15023.
27 Saito M, Gao J, Basso K, et al. A signaling pathway mediating downregulation of BCL6 in germinal center B cells is blocked by BCL6 gene alterations in B cell lymphoma. Cancer Cell 2007;12: 280-292.

28 Keller CE, Nandula S, Vakiani E, et al. Intrachromosomal rearrangement of chromosome 3q27: an under recognized mechanism of BCL6 translocation in B-cell non-Hodgkin lymphoma. Hum Pathol 2006;37: 1093-1099. 